\title{
Gait Recognition using Shoulder Body Joint
}

\author{
Jyoti Bharti \\ MANIT \\ Bhopal,India
}

\author{
M. K. Gupta \\ MANIT \\ Bhopal,India
}

\begin{abstract}
This paper introduces a new gait recognition approach based on shoulder body joint using in intersection point. This approach is tested on a CASIA database of video sequences, corresponding 10 different subject of people. Obtained better recognition rate as compared to other methods. Consider two component of human body. The first component is shoulder and second component is feet. The second component is subdivided into two parts i.e. toe and heel of both right and left leg. Our proposed method increase the matching accuracy with 98 and 100 percent.
\end{abstract}

\section{Keywords}

Gait recognition, Intersection, Recognition Rate,,biometric.

\section{INTRODUCTION}

In the present world scenario, Security is a major aspect in all fields. In response to this demand new technologies are being developed to achieve requisite level of security. One of these technologies is referred to as biometrics. Biometrics refers to the automatic recognition of a person based on their physiological or behavioral characteristics. Physical and behavioral characteristics of each and every people are different and unique. Human gait is an important and promising biometric resource for identification. The term gait was first demonstrate by Johansson in 1970[2]. The gait is defined as "Gait is a particular way or manner of moving on foot". Human gait has a unique personal characteristic and cyclic in nature[1]. Face, fingerprint recognition, iris recognition can't work well from a large distances as well as on degraded images in present scenario security is one of the challenging issues in all field. In proposed to this demand new technologies are being developed energy day to security. The most popular level of security. The most popular technology is adopted by many agencies, based on biometric traits. Biometric traits can be categorized by physiological and behavioral. Physical and behavioral characteristic of each people is unique and can not be copied or faked. Human gait is one of the promising biometric traits for identification gait introduction by Johnson in 1970 [3]. The distances between the cameras and the people are often large. In these situations, gait recognition can work well when image can be captured from a distant camera, without drawing the attention of the observed subject [4]. A new gait recognition methodis proposed in this paper which is based on an angle at intersecting points and fuzzy inference system as a classification to achieve better gait recognition rate.

This paper is organized as follows. Section II Summaries some related existing methods for human gait recognition. Gait, fuzzy logic, fuzzy inference system and its methods are described in section III. Section IV provides our proposed method. Experimental results \& analysis are presented in section V, followed by Conclusions \& future scope in Section VI.

\section{RELATED WORK}

Authors can work on various algorithm and method for identification using gait. The images can be used by authors is silhouette and MCI, GEI etc.[5,6,8] few of them used the body joint kinematics. The feature values of body joints can be extracted with the help of and other components $[14,7,9]$. Geometric characteristics like angle length etc. are used on body joint. The feature values was extracted and achieved good recognition rate $[10,9]$. It is concluded that from related work is that geometric characteristic produce unique feature values and achieved better RR. So that in this paper geometric methods is used.

The paper was based on Physiological Variation in Ankle. Ankle joint play an important role in gait, balance and many activities of daily living[16].

\section{H UMAN GAIT}

The definition of Gait is defined as "A peculiar way or manner one walks". Gait recognition is a multistage process[13]. Analysis of walking pattern is a gait cycle. The style of walking or gait cycle of every person is unique. [11].Human gait is the repeated motion of the body parts. Mostly there is no much more changes in head and shoulder motion as compare to hand and legs. The repeated motion part of the body forms a gait cycle. A single Gait cycle or stride is defined as a movement when initial position of a heel comes back again as shown in fig.1. The single gait cycle is further divided into two phases:

1 Stance Phase:Foot in contact with the ground loading response, Mid-stance, Terminal stance, and Pre-swing[12] 2. Swing Phase: Foot not in contact with the ground. Initial swing, Middle swing, and Terminal swing[12].

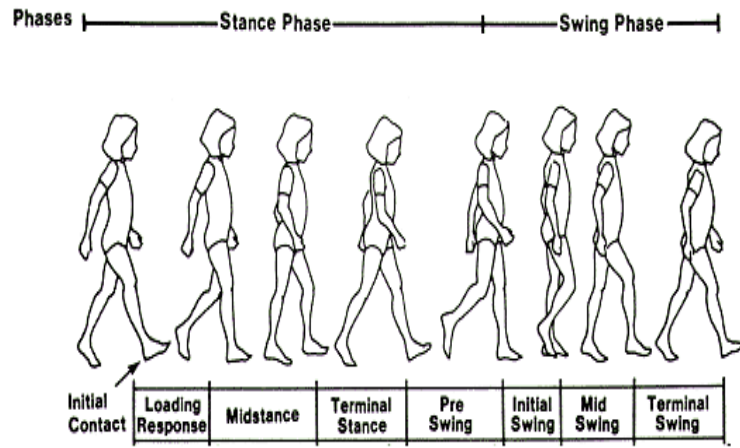

Fig1. Representation of subject moving through the gait cycle.

\section{PROPOSED METHODOLOGY}

The most popular level of security. The most popular technology is adopted by many agencies, based on biometric traits. Biometric traits can be categorized by physiological and 
behavioral. Physical and behavioral characteristic of each people is unique and can not be copied or faked. Two components of human body has been consider. First component is shoulder and another component is feet. Second component is subdivided into toe and heel of both left and right feet. Total five control or feature point are formed and insert a white dot point on that control point $s$ which is shown in fig. 2[9].

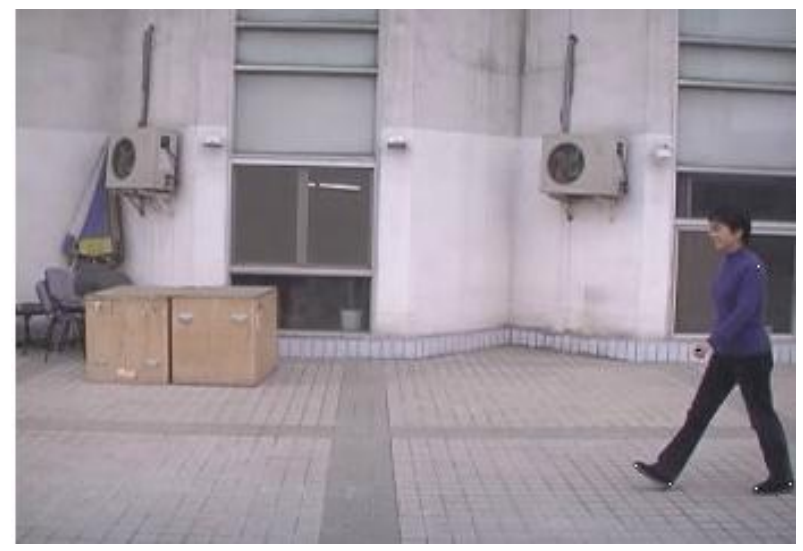

Fig. 2. White dot points on shoulder and foot body joint.

These white dotted frames of each individual inputted in proposed gait system, which is designed in MATLAB7.5 for gait recognition. Two triangles are created on using these five featured point. First triangle is drawn between shoulder and two heels of both feet (right heel and left heel) and $2^{\text {nd }}$ triangle is created between same hand and two toe of both feet (right toe and left toe). Then two intersecting points are computed between these two triangles as shown in figure 3 below:

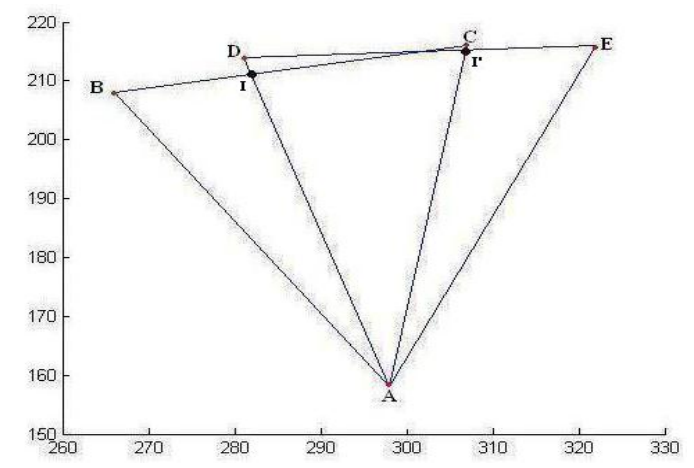

Fig. 3. i and $r$ are intersecting points between $\Delta$ 's ABC \& ADE.

I \& $\mathrm{r}$ are two intersecting points which have to be computed using parametric line equation. The extracted feature values are the Intersecting Points of the two Triangles. Triangle ABC and ADE are intersecting at three places. But only two intersecting points ( $\mathrm{i}$ and $\mathrm{r}$ ) are considered, because these intersecting points are on that lines where toe and hill. Here point A represent Hand and point B,C represents toe of both feet(left and right),point D,C represents heel of both feet(Left and Right) shown in figure 3 . Only intersecting points of base line of triangles (points of intersecting at line $\mathrm{BC}$ and line DE).
For finding the Intersecting points $\mathrm{i}$ and $\mathrm{r}$ of two triangles first we need equation of the line $\mathrm{BC}, \mathrm{AD}, \mathrm{AC}$ and $\mathrm{DE}$. So we make the equation of line

$$
\mathrm{Y}=\mathrm{m} . \mathrm{X}+\mathrm{b}
$$

where $\mathrm{m}$ is slop of line and $\mathrm{b}$ is intercept.

Slop of line is calculated using following formula

$$
\begin{aligned}
& \mathrm{m}=\left(\mathrm{y}_{\mathrm{i}}-\mathrm{y}_{\mathrm{i}-1}\right) /\left(\mathrm{x}_{\mathrm{i}}-\mathrm{x}_{\mathrm{i}-1}\right) \\
& \mathrm{m}=(\mathrm{y} 2-\mathrm{y} 1) /(\mathrm{x} 2-\mathrm{x} 1)
\end{aligned}
$$

Intercept is calculated using following formula

$$
\mathrm{b}=\mathrm{y}-\mathrm{m} \cdot \mathrm{x}
$$

\[ \mathrm{b}=\mathrm{y}-\mathrm{m} . \mathrm{x} \]
where $\mathrm{x}$ and $\mathrm{y}$ are the point on line.

So we have four equations of line.

$$
\begin{gathered}
\mathrm{Y}_{1}=\mathrm{m} 1 \cdot \mathrm{X} 1+\mathrm{b} 1 \\
\mathrm{Y}_{2}=\mathrm{m} 2 \cdot \mathrm{X} 2+\mathrm{b} 2 \\
(5) \\
\mathrm{Y}_{3}=\mathrm{m} 3 \cdot \mathrm{X} 3+\mathrm{b} 3 \\
(6) \\
\mathrm{Y}_{4}=\mathrm{m} 4 \cdot \mathrm{X} 4+\mathrm{b} 4 \\
(7)
\end{gathered}
$$

Eq. 4, 5, 6 and 7 represents the equations of line of $\mathrm{BC}, \mathrm{AC}$, $\mathrm{AD}$ and DE respectively. $\left(\mathrm{m}_{1}, \mathrm{~b}_{1}\right),\left(\mathrm{m}_{2}, \mathrm{~b}_{2}\right),\left(\mathrm{m}_{3}, \mathrm{~b}_{3}\right)$ and $\left(\mathrm{m}_{4}\right.$, $\mathrm{b}_{4}$ ) are the pair of slop and intercept of lines BC, AC, AD and DE respectively.

The intercept $b_{1}, b_{2}, b_{3}$ and $b_{4}$ are calculated using following formulas

$$
\begin{aligned}
& \mathrm{b}_{1}=\mathrm{y}_{1}-\mathrm{m} 1 \mathrm{x}_{1} \\
& \mathrm{~b}_{2}=\mathrm{y}_{2}-\mathrm{m} 2 \mathrm{x}_{2} \\
& \mathrm{~b}_{3}=\mathrm{y}_{3}-\mathrm{m} 3 \mathrm{x}_{3} \\
& \mathrm{~b}_{4}=\mathrm{y}_{4}-\mathrm{m} 4 \mathrm{x}_{4}
\end{aligned}
$$

At the point of intersection of lines $\mathrm{BC}$ and $\mathrm{AD}$ the $\mathrm{x}$ and $\mathrm{y}$ coordinates are same $\left(X_{1}=X_{3}\right.$ and $\left.Y_{1}=Y_{3}\right)$. So for finding Intersecting Point $\mathrm{i}$ of line $\mathrm{AD}$ and $\mathrm{BC}$ we equate the eq. 4 and 6.

$$
\begin{aligned}
& \mathrm{m}_{1} \cdot \mathrm{X}_{1}+\mathrm{b}_{1}=\mathrm{m}_{3} \cdot \mathrm{X}_{3}+\mathrm{b}_{3} \\
& \text { but } \left.\left(\mathrm{X}_{1}=\mathrm{X}_{3}\right)\right\} \\
& \quad \text { or } \\
& \mathrm{X}_{1}=\left(\mathrm{b}_{3}-\mathrm{b}_{1}\right) /\left(\mathrm{m}_{1}-\mathrm{m}_{3}\right)
\end{aligned}
$$

By solving eq. 12 get the value of $\mathrm{x}$ coordinate of point i.e substation $\mathrm{X}_{1}$ value in eq. 4 or 6 then y coordinate of point is exteacted. The coordinate of point $\mathrm{i}$ is $\left(\mathrm{X}_{1}, \mathrm{Y}_{1}\right)$.

Similar process is used for finding the others Intersecting Point $r$ of Line DE and AC. The coordinate of point $r$ is (Xr,Yr)

So we get the Intersecting Points $\mathrm{i}\left(\mathrm{X}_{\mathrm{i}}, \mathrm{Y}_{\mathrm{i}}\right)$ and $\mathrm{r}\left(\mathrm{X}_{\mathrm{r},}, \mathrm{Yr}\right)$. after that mean values of two intersecting point of an individual subject are computed as shown in equation 14 .

$\bar{x}=\frac{1}{n} \sum_{1}^{n} x_{i}$

\subsection{Proposed Algorithm.}

1. Select input subject frames are(17,20,23,25 and 27).

2. Convert color image into gray scale image.

3 . Compute pixel values of white dotted point on body joint.

4. Two triangle are constructed .

5. Calculated two intersection point for these triangle.

6. Mean values are computed.

7. These mean values are used for recognition by using nearest neighbor classifier.

8 . The mean values is compared with in. if the mean values is found then the person is guaranteed to found. It not person not found.

9. Repeat the process for another user. 


\section{EXPERIMENTAL RESULT AND}

\section{ANALYSIS.}

The algorithm is implemented on matlab 7.5 CASIA data base is used.[15]. Ten different subject (used) are selected with two side views $\mathrm{S} 1$ \& $\mathrm{S} 2$. S1 sides when person is walking from Right to Left and S2 side, when person walking from left to Right. Stored database is made up of 23 frames ( 23 frame is expected to be a complete gait cycle). The data base is of there type $\mathrm{S} 1$ individual, $\mathrm{S} 2$ individual and $\mathrm{S} 1+\mathrm{S} 2$ (data values are from $\mathrm{S} 1$ and $\mathrm{S} 2$ both ). Five different type of frames are selected as a input frames. Types of input frames are 17,20,23 and 25,27 frames. 17, 20 frames are incomplete gait cycle. 23 is a complete gait cycle. 25 and 27 is over gait cycle frames (i.e. more than one gait cycle frame ). These five type of input frame are applied on the database. The RR is computed in the form of Rank-1 (R1) and Rank-5 (R5). Show in table 1. Table 1 shows the simulation results of an algorithm for Fuzzy. In this table Recognition Rate experimental for 17, 20, 23, 25 and 27 frames for R1 and R5 for all four sides $(\mathrm{S} 1, \mathrm{~S} 2, \mathrm{~S} 1(\mathrm{~S}+\mathrm{S} 2)$ and $\mathrm{S} 2(\mathrm{~S} 1+\mathrm{S} 2)$ ) are shown. The last column of table shows the average RR of all sides for particular frame and rank.

\begin{tabular}{|c|c|c|c|c|c|c|}
\hline $\begin{array}{c}\text { Frame } \\
\text { S }\end{array}$ & $\begin{array}{c}\text { Ran } \\
\text { k }\end{array}$ & Side1 & $\begin{array}{c}\text { Side } \\
\mathbf{2}\end{array}$ & \multicolumn{2}{|c|}{ Side(S1+S2) } & $\begin{array}{c}\text { Avg(\% } \\
\text { ) }\end{array}$ \\
\hline & & & & S1 & S2 & \\
\hline $\mathbf{2 3}$ & R1 & $0 \%$ & $10 \%$ & $10 \%$ & $10 \%$ & $7.50 \%$ \\
\hline & R5 & $50 \%$ & $70 \%$ & $40 \%$ & $60 \%$ & $55.00 \%$ \\
\hline $\mathbf{2 0}$ & R1 & $60 \%$ & $10 \%$ & $60 \%$ & $20 \%$ & $37.50 \%$ \\
\hline & R5 & $100 \%$ & $60 \%$ & $100 \%$ & $60 \%$ & $80.00 \%$ \\
\hline $\mathbf{1 7}$ & R1 & $90 \%$ & $60 \%$ & $60 \%$ & $60 \%$ & $67.50 \%$ \\
\hline & R5 & $100 \%$ & $\begin{array}{c}100 \\
\%\end{array}$ & $100 \%$ & $\begin{array}{c}100 \\
\%\end{array}$ & $100 \%$ \\
\hline $\mathbf{2 5}$ & R1 & $20 \%$ & $30 \%$ & $10 \%$ & $30 \%$ & $22.50 \%$ \\
\hline & R5 & $100 \%$ & $90 \%$ & $100 \%$ & $90 \%$ & $95.00 \%$ \\
\hline $\mathbf{2 7}$ & R1 & $90 \%$ & 100 & $100 \%$ & 100 & $97.50 \%$ \\
& & & $\%$ & & $\%$ & \\
\hline & R5 & $100 \%$ & 100 & $100 \%$ & 100 & $100 \%$ \\
& & & $\%$ & & $\%$ & \\
\hline
\end{tabular}

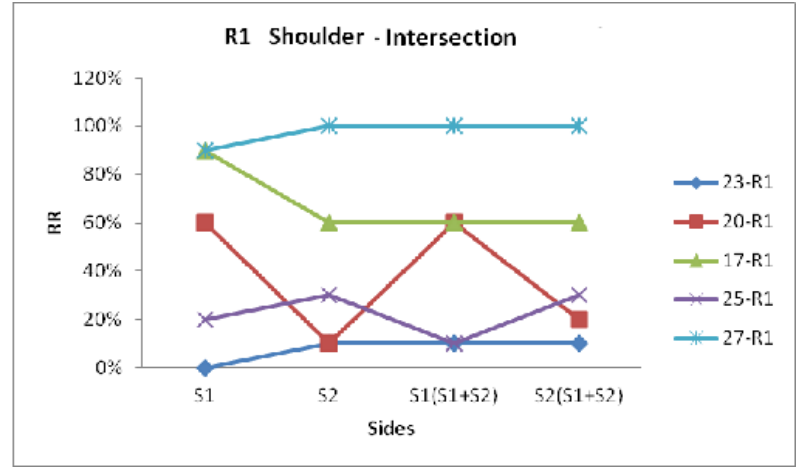

Figure 4: Comparison of RR of all frames for R1.

As per fig 4,it is analyzed that 27 frames gives best RR for all sides $(100 \%)$. For 17 frames RR is $90 \%$ for $\mathrm{S} 1$ (Ind) and $60 \%$ for other sides. It is satisfactory. RR for 20 frames is good $(60 \%)$ for S1 sides, but not good at S2 sides.

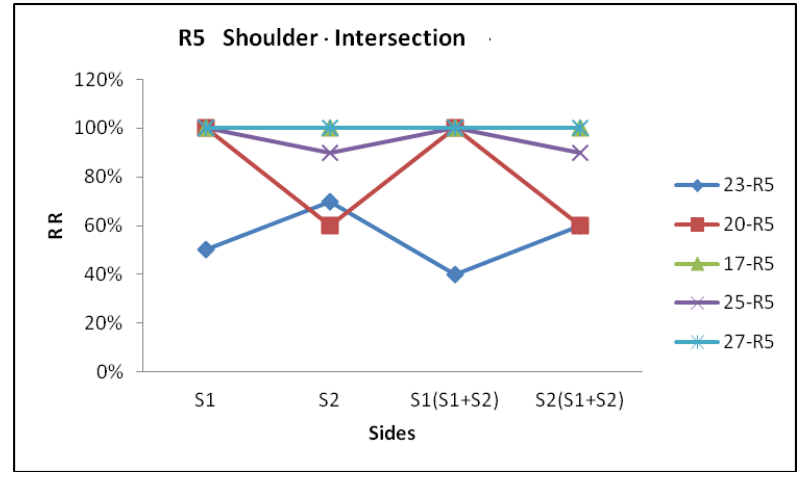

Figure 5 : Comparison of RR of all frames for R5 .

As per observation of fig.5 RR is best (100\%) at 17 and 27 frames, for all sides. And 100\% RR for S1 side (Ind, S1+S2) at 20 and 25 frames. RR for 23 frames is satisfactory at $\mathrm{S} 2$ but not good at $\mathrm{S} 1$ and $(\mathrm{S} 1+\mathrm{S} 2)$ the RR is $50-70 \%$.

figures 6 shows the graphical comparison of Avg RR of R1 \& $\mathrm{R} 5$ with respect to all frames

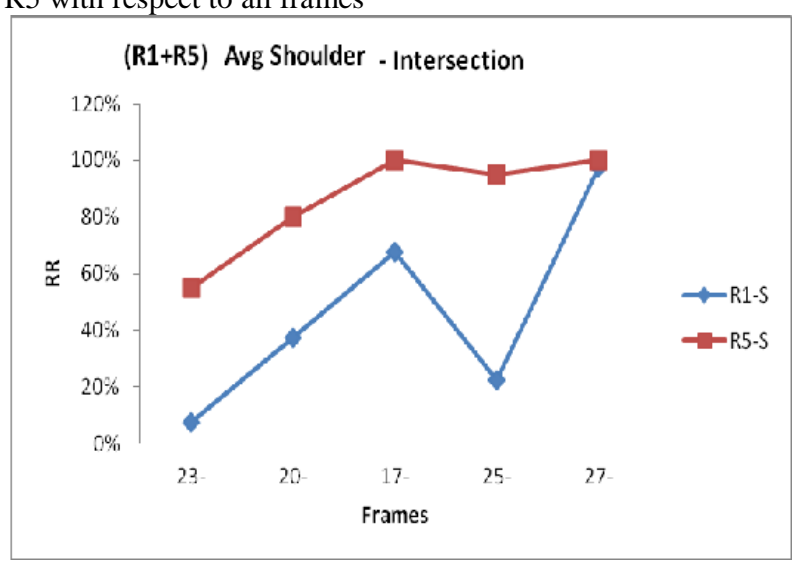

Fig 6.: Comparison of Avg RR of Avg R1 \& R5 for all frames.

Intersection method obtain best RR for 17, 25 and 27 frames from R5(95-100\%). For these frames RR is almost $100 \%$. R1 also produces best RR (97\%) for 27 frames and good RR (67\%) for 17 frames. RR for 23 and 20 frames lies between $50-80 \%$ for R5. RR of 23, 20 and 25 frames for R1 is poor ad below $40 \%$. Over all R5 is better than R1.

Table 2: Best frame and RR (R1 \& R5)

\begin{tabular}{|c|c|c|c|c|}
\hline $\begin{array}{c}\text { Metho } \\
\mathrm{d}\end{array}$ & $\begin{array}{c}\text { Ra } \\
\mathrm{nk}\end{array}$ & $\begin{array}{c}\text { Best } \\
\text { Fram } \\
\text { es }\end{array}$ & $\begin{array}{c}\text { High } \\
\text { est } \\
\text { RR }\end{array}$ & $\begin{array}{c}\text { Avera } \\
\text { ge RR }\end{array}$ \\
\hline \multirow{2}{*}{$\begin{array}{c}\text { Shoul } \\
\text { der }\end{array}$} & R1 & 27 & $100 \%$ & $\begin{array}{c}97.50 \\
\%\end{array}$ \\
\cline { 2 - 5 } & R5 & $\begin{array}{c}17, \\
27\end{array}$ & $100 \%$ & $100 \%$ \\
\hline
\end{tabular}


Table 2 depicts that for R1 and R5 27 frames is best and 17 frame is also best for R5. The higher avg RR for R1 and R5 is $98 \%$ and $100 \%$ is respectively.

Table .3 Experimental results compared with other Algorithm

\begin{tabular}{|l|c|c|}
\hline Algorithm & \multicolumn{2}{|c|}{ CCR } \\
\hline $\begin{array}{l}\text { Method based on } \\
\text { Positioning body joints[10] }\end{array}$ & \multicolumn{2}{|c|}{$78 \%$} \\
\hline $\begin{array}{l}\text { Method based on dynamic } \\
\text { body Parameters[9] }\end{array}$ & \multicolumn{2}{|c|}{$78 \%$} \\
\hline $\begin{array}{l}\text { Shoulder intersection } \\
\text { method }\end{array}$ & $98 \%$ & $100 \%$ \\
\hline
\end{tabular}

Table 3 shows the comparison of proposed method with other methods. From this table it is clear that highest RR for is achieved for R1 by shoulder intersection method (98\%) with Fuzzy logic classifier and for rank-5 second highest RR (100\%).

\section{CONCLUSION}

It is concluded that five body joint, triangle and geometric characteristic extract the unique feature values. These feature are used for person identification by using nearest neighbor classifier. Which produce higher RR i.e. $98 \%$ for R1 and $100 \%$ for R5. 27 and 17 frames is a incomplete gait cycle. Other frames also produce better RR (Recognition Rate) .it is experimentally prove that intersection is better method to generate best RR for incomplete gait cycle also.

\section{FUTURE WORK}

In present work, the Shoulder body joint is used for identification. Other body joints like Knee, Palm, Elbow, Head, Wrist and Neck. may be combining with Shoulder and the feature values may be extracted for identification. The RR may be predicted for identification of human is based on the feature values of various body joints and the better results may be obtained. This may enhance the efficiency and the correctness or absolute identification can be predicted of a human being, which may be used in defense/military applications and other agencies.Hence it is concluded that algorithm works satisfactorily under varying condition and improve the recognition rate, and is stable for large identification systems.

\section{REFERENCES}

[1] M.P. Murray, "Gait as a total pattern of movement", American journal of Physical medicine 46(1):290-333, 1967.

[2] G.Johnsson, "Visual perception of biological motion and a model for its Analysis, Perception Psychophys", IEEE conference on intelligent control and automa,vol14(2) 201-211, 1973.

[3] Weiinin, Ying, Hongzhe, Lun', Zluliang, Fengjun, "New Approach of $\mathrm{G}$ ait Recognition For Human ID", IEEE
International conference on signal processing, vol 3(2715p),pp 199-202, 2004.

[4] Xiaxi Huang and Nikolaos V. Boulgouris, "Gait Recognition Using Multipal Views", IEEEConferenceon Acoustics,speech and signal Processing( ICASSP), vol. 39, pp. 969-979, 2008.

[5] X.Yang,Y.Zhou,T.Zhang,J.Yang, "Gabor phase based gait recognition", IEEE Journal on pattern analysis and machine,Vol.44 No. 10,8th May 2008.

[6] Khalid Bashir, Tao Xiang, Shaogang Gong: "Feature selection on gait energy image for human identification",IEEE International Conference on Acoustics, Speech, and Signal Processing ,pp 44-50,2008

[7] Xuelong Li, Stephen J. Maybank,Shuicheng Yan, Dacheng Ta, and Dong Xu,,"Gait Components and Their Application to Gender Recognition", IEEE Transactions on Systems, Man, and Cybernetics Part C Applications and Reviews, vol. 38, no. 2, March 2008.

[8] Byungyun Lee, Sungjun Hong, Heesung Lee, Euntai Kim, “Gait Recognition System using Decision-Level Fusion", $5^{\text {th }}$ IEEE conference on industrial electronics and application,pp.313-316,2010.

[9] Jasvinder pal singh and Sanjeev jain, "Person Identification Based on Gait using Dynamic Body Parameters", IEEE International Conference on Trendz in Information Sciences \& Computing (TISC),pp: $248-252, \quad 2010$

[10] Ai-Hua Wang. Ji-Weiliu. "A Gait Recognition Method Based On Positioning Human Body Joint".IEEE International Conference On wavelet analysis and Pattern Recognition,vol 3,pp.1067-1071,2007.

[11] James R. Gage,Peter A.Deluca ,Thomas S.Renshaw "Gait Analysis Principles and Applications",The Journal of bone and joint surgery, vol. 77,1607-1623, 1995.

[12] James R. Gage, Peter A. Deluca and Thomas S. Rensha, "Gait Analysis: Principles and Applications", Journal of Bone \& Joint Surgery, Volume 77, Issue 10, pp 16071623, October 1995.

[13] Nikolaos V. Boulgouris, Dimitrios Hatzinakos, and Konstantinos N. Plataniotis, "A challenging signal processing technology for biometric identification", IEEE Signal Processing Magazine, pp 56-70, November 2005.

[14] Joao P. Ferreira, Manuel Crisostomo, A. Paulo Coimbra, David Carnide, and Antonio Marto:"A Human Gait Analyzer",IEEE international symposium on intelligent signal processing, October 2007.

[15] Center for Biometrics and Security Research (CBSR).

[16] Zhang Zhen, Wang Zhen, Yao Songli, Zhang Yanan and Qian, Jinwu, "Research on Control of an Exoskeletal Ankle with Surface Electromyography Signals", The second International Conference on Bioinformatics and Biomedical Engineering(ICBBE), pp. 1301 - 1304, 2008. 